\title{
In-situ Observation of Co-Ce Coated Metallic Interconnect Oxidation Combined with High-Resolution Post Exposure Analysis
}

\author{
Stéphane Poitel ${ }^{\mathrm{a}, \mathrm{b}}$, Zhu-Jun Wang ${ }^{\mathrm{c}}$, Marc Georg Willinger ${ }^{\mathrm{c}, \mathrm{d}}$, Jan Van herle ${ }^{\mathrm{b}}$, Cécile \\ Hébert ${ }^{\mathrm{a}, \mathrm{e}}$
}

(a) Centre Interdisciplinaire de Microscopie Electronique (CIME), Ecole Polytechnique Fédérale de Lausanne, CH-1015 Lausanne, Switzerland

(b) Group of Energy Materials (GEM), Faculty of Engineering Sciences (STI), STI-SCIJVH, Ecole Polytechnique Fédérale de Lausanne, CH-1951 Sion, Switzerland.

(c) Fritz Haber Institute of the Max Planck Society, Department of Inorganic Chemistry, Faradayweg 4-6, D - 14195 Berlin, Germany

(d) Department of Colloid Chemistry, Max Planck Institute of Colloids and Interfaces, Research Campus Golm, D - 14476 Potsdam, Germany

(e) Laboratoire de spectrométrie et microscopie électronique, Intistute of Physics, Ecole Polytechnique Fédérale de Lausanne, CH-1015 Lausanne, Switzerland

Oxidation of Sanergy SSHT steel with Ce-Co coating, used as interconnect material, was observed in-situ in a modified environmental scanning electron microscope (ESEM) at nominal temperature between $800^{\circ} \mathrm{C}$ and $900^{\circ} \mathrm{C}$ under $33 \mathrm{~Pa}$ of oxygen, for different durations (up to $60 \mathrm{~h}$ ). After these in-situ observations, lamellas of the observed target areas were prepared using a focused ion beam (FIB). This allowed the evaluation in the cross section of the final composition of the oxidation layers of the steel by scanning transmission electron microscopy (STEM) and energy dispersive $\mathrm{x}$-ray analysis (EDX), of the same zone observed directly on the surface by ESEM.

Results show the diffusion of manganese and iron towards the cobalt coating. Underneath, chromia scale forms. Under the applied conditions, the very thin cerium layer does not prevent the diffusion of other elements from the steel. Niobium (with silicium) and titanium form oxidized precipitates in the steel just below the chromia scale.

\section{Introduction}

Interconnect development for SOFC stacks remains a challenging and key part towards the final product deployment. The interconnects have to be cheap, mechanically and chemically stable at the working temperatures $\left(650-850^{\circ} \mathrm{C}\right)$ for long operating times including transients, and their surface as conductive as possible in reducing and oxidising atmospheres. Ten years ago, considering all requirements and constraints, Fergus et al. [1] concluded that chromia-forming steels appeared the most suitable if research were conducted to decrease their cost - this statement still seems to hold. Two major drawbacks arise from using high-chromium-content steel: (i) chromium evaporation at working temperature which then contaminates the cathode materials [2] and (ii) increase of the contact resistance with time which increases the overall resistive loss of the SOFC stack. Reviewing the chromium poisoning problem [3], Fergus et al. suggested that the 
choice of cathode and electrolyte materials can help reducing $\mathrm{Cr}$ poisoning. However, it does not solve the problem. A systematic study of the influence of alloying on $\mathrm{Cr}$ evaporation demonstrates that the outer oxide scale formed at high temperature and the $\mathrm{Cr}$ evaporation rate depend on the alloy [4]. In particular, cobalt and manganesecontaining alloys and aluminium-based alloys show lower $\mathrm{Cr}$ evaporation rates. The formation of $\mathrm{Co}_{3} \mathrm{O}_{4}$ spinel and alumina scales are responsible for this. Hence, choosing an adapted alloy is reducing the problem but not sufficient. Analysing the oxide layers which are the most effective when bare alloys are oxidised also helped in choosing an appropriate coating, as confirmed by others [5]. Stanislowski et al. showed that $\mathrm{Co}, \mathrm{Ni}$ and $\mathrm{Cu}$ coatings were capable of reducing $\mathrm{Cr}$ evaporation, maintaining high scale conductivity and stability for $1200 \mathrm{~h}$ at $800^{\circ} \mathrm{C}$ [6]. Subsequently, several coating materials and processes were developed to obtain regular, homogeneous layers on steel interconnects [7][8][9][10].

Cobalt-containing coatings developed since 2008 have demonstrated to reduce $\mathrm{Cr}$ evaporation, decrease areal specific resistance (ASR) and increase corrosion resistance [11]. Studies have confirmed the beneficial effects of cobalt coating for several steel substrates [10] and its adaptability to industrial production [12].

From the comparison of the oxidation between uncoated and Co-coated SSHT steel in a time-resolved study, using STEM-EDX, mass gain and ASR measurement, Froitzheim et al. suggested an oxidation model [13]. During the initial stage of the corrosion, the Co-layer is oxidized first to $\mathrm{CoO}$ and then to $\mathrm{Co}_{3} \mathrm{O}_{4}$. Interdiffusion between $\mathrm{Fe}$ and $\mathrm{Co}$ occurs before the oxidation front reaches the interface between the coating and the bulk. During a second stage, a chromia layer begins to form between the steel and the coating while the latter develops two layers: one of $\mathrm{Co}_{3} \mathrm{O}_{4}$ and one of $(\mathrm{Co}, \mathrm{Fe})_{3} \mathrm{O}_{4}$. After a week of oxidation (168h), a layer of chromia is observable and diffusion of $\mathrm{Fe}$ and $\mathrm{Mn}$ into the coating results in a $(\mathrm{Co}, \mathrm{Fe}, \mathrm{Mn})_{3} \mathrm{O}_{4}$ top layer. At the same time, thin $\mathrm{Cr}_{2} \mathrm{MnO}_{4}$ can be identified below the chromia layer due to the diffusion of $\mathrm{Mn}$ from the steel bulk. In the final stage, the chromia layer is thickening while the Cr-Mn spinel layer is dissolved and the Co-Mn-Fe top spinel layer stays stable.

More detailed studies [14], [15] about the microstructures of Co-coating as a function of time revealed that chromia begins to form within 4 minutes at high temperature and that also a thin $\mathrm{CoCr}$ layer can be observed between the chromia layer and the coating.

For a cobalt coating thickness $>2 \mu \mathrm{m}$, the difference in thermal expansion coefficient (TEC) of cobalt and steel may result in high stress [16]. The cobalt-coating does not prevent oxide scale growth which finally, increases the ASR. Addition of Mn to such a thick coating seems to reduce those drawbacks. Moreover, a higher Mn-content in steels leads to lower $\mathrm{Cr}$ evaporation owing to the build-up of a thicker $\mathrm{MnCrO}$ spinel layer on top [5]. This lead to the development of a Co-Mn-based spinel coating which demonstrates many advantages: low ASR, Cr retention, reduction in oxidation rate and good thermal stability [8][9][17][18].

Fe-doped Mn-Co spinel was also found to be an efficient coating: preventing $\mathrm{Cr}$ diffusion,with good steel adhesion and thermal cycling resistance [19]. However, substrates with higher Mn-content were necessary to obtain a sufficiently low electric resistance with the contact layer. Wang et al. [20] studied the reaction layer between Co- 
Mn-coating and the chromia layer. Two inter-layers were identified: one formed by Co diffusing from the coating and one formed by $\mathrm{Cr}$ diffusing from the chromia. Both layers contain $\mathrm{Mn}, \mathrm{Co}, \mathrm{Cr}$ and $\mathrm{O}$ but in different proportions. They also showed that addition of $\mathrm{Ti}$ or $\mathrm{Fe}$ as dopant in the coating reduces the reaction rate and hence increases the lifetime of the interconnect. Doping Ni-Co-O coating with Fe makes it more efficient too: it leads to a more stable spinel oxide and lower ASR value [21]. However, Grolig et al. [22] found that iron was not beneficial to the coating and that Ce acts as a barrier against iron diffusion into Co-Mn spinel which allows to maintain a lower ASR.

$\mathrm{La} / \mathrm{Co}$-double layer coating was also proven to be efficient in decreasing steel oxidation and avoiding $\mathrm{Cr}$ evaporation [23]. A more complex combination with La, such as a double layer coating of $\mathrm{Co} / \mathrm{LaCrO}_{3}$ [24] showed high conductivity and low $\mathrm{Cr}$ evaporation after 900 hours of ageing. Post-test analyses showed the presence of three layers: chromia, $\mathrm{Fe}-\mathrm{Co}$ oxide, and $\mathrm{Co}_{3} \mathrm{O}_{4}$ respectively, from bulk to surface. The combination of $\mathrm{La}_{2} \mathrm{O}_{3}$ and $(\mathrm{Co}, \mathrm{Mn})_{3} \mathrm{O}_{4}$ coatings avoids the formation of a chromia layer (which is present in the case of $(\mathrm{Co}, \mathrm{Mn})_{3} \mathrm{O}_{4}$ coating alone) and also prevents the formation of an iron oxide layer in dual atmosphere (which appears in the case of $\mathrm{La}_{2} \mathrm{O}_{3}$ coating alone) [25].

Cerium was also investigated as coating material. It tends to segregate at $\mathrm{Cr}-\mathrm{Mn}$ grain boundaries, blocking the diffusion path for oxygen and so decreasing the oxidation rate [26]. $\mathrm{CeO}_{2}$ coatings of various thicknesses demonstrated a decrease in oxidation rate [27]. However, in that study, no $\mathrm{Cr}$ evaporation measurement was conducted. Thus, the results may be misinterpreted as $\mathrm{Cr}$ evaporation was not taken into account.

Froitzheim et al. [28] first reported a $800 \mathrm{~nm}$ Co-coating on a $10 \mathrm{~nm}$ Ce-coating to efficiently decrease Cr-evaporation. The Ce-layer increases the high temperature corrosion resistance. It was later demonstrated that it prevents $\mathrm{Cr}$ diffusion to the top layer [11]. Several studies confirmed the beneficial effects of Ce [29] [30], even in the case of discrete particles rather than as a Ce-layer [31]. Ce was also shown to act as diffusion barrier against iron diffusion from the steel [22].

Recently, the application of such coatings for Intermediate Temperature SOFC (ITSOFC) with working temperature between $650^{\circ} \mathrm{C}$ and $750^{\circ} \mathrm{C}$ was studied [32]. The decrease in temperature leads to a change in microstructure of the coating. Ce initially acts as a barrier for $\mathrm{Fe}$-diffusion and decreases the oxidation rate at $750^{\circ} \mathrm{C}$. At $650^{\circ} \mathrm{C}$, no influence of $\mathrm{Ce}$ is observed. The $\mathrm{Co}$ and $\mathrm{Co}-\mathrm{Ce}$ coating effectiveness for reducing $\mathrm{Cr}$ evaporation at 650 and $750^{\circ} \mathrm{C}$ was demonstrated. The temperature influences the ASR measurements. The study [32] suggests that the chromia layer remains responsible for the ASR increase.

The role of other additives in steels for interconnects has also been studied. $\mathrm{Nb}$ and $\mathrm{Ti}$ form oxide phases at the interface between the oxide layers and the substrate and act as diffusion barrier [33]. The Nb-to-Ti ratio should be sufficiently high to decrease the oxidation rate. A Nb-rich phase also demonstrates the ability to capture Si [17], preventing the formation of insulating silica. This is a problem specific to Si-containing steel: insulating $\mathrm{SiO}_{2}$ particles or layers may form at the interface between the steel and coating, increasing the ASR [31]. 
Studying interconnects and their coatings has to be performed with care, especially regarding the temperature, atmosphere and measurement conditions. Interconnects aged in dual atmosphere presented a different surface compared to interconnects aged in air only [34]. Testing interconnects in dual atmosphere cannot be realized for all analysis methods. The difference to dual atmosphere exposure has to be kept in mind when drawing conclusions from ageing studies in air. A study of the oxidation of several bare steels as SOFC interconnects revealed that Cr-evaporation has to be taken into account when measuring the mass gain [5] to calculate the oxidation rate of the steel. Neglecting it may lead to several tens of percent error on the final results. It was also demonstrated that the Cr- evaporation is more influenced by the temperature than the oxidation rate [35]. Indeed, lowering the temperature by $100 \mathrm{~K}$ decreases the oxidation rate by a factor 5 while the Cr- evaporation is reduced only by a factor 2-3. This means that the interpretation of data obtained at higher temperature during accelerated testing can be challenging and even misleading since the relative importance of the various phenomena depends on temperature.

In his master thesis [36], Skott studied the oxidation of Co-coating on SSHT steel with XRD and environmental SEM. The comparison of coated and uncoated steel at temperatures between $800^{\circ} \mathrm{C}$ and $1000^{\circ} \mathrm{C}$ in $600 \mathrm{~Pa}$ of oxygen together with post-test analysis confirmed the beneficial effect of cobalt regarding Cr-retention. A faster growth of chromia compared to $(\mathrm{Co}, \mathrm{Mn})_{3} \mathrm{O}_{4}$ was evidenced for higher temperature. From the comparison between this work with in-situ SEM and thermogravimetric experiments, he concluded that the partial pressure of oxygen did not influence the growth rate of the two oxide layers. Other studies also estimate that the lower pressure in the microscope chamber does not fundamentally alter the reaction [37], [38]. However, this influence of lower exposure pressure is subject to controversies. Jeangros in his thesis using environmental TEM, showed that a reaction rate may depend on the pressure [39].

Understanding the oxidation of these recent state-of-the-art coatings requires a combination of techniques: thermogravimetry to record mass changes during oxidation and calculate reaction rates, SEM to analyse the cross section of coatings after oxidation, STEM-EDX to analyse finer microstructures. EELS was used in a few studies while ESEM is almost completely new in this field.

While the beneficial effect of Ce-Co-coating on steels for use as interconnect seems acknowledged, the ways how the coating oxidises and provides its advantages are not fully understood yet. Gaining a better understanding is important to evaluate whether the same or similar coatings with satisfying properties under operation would also work on lower cost steels.

The aim of this article is to demonstrate the relevance of in-situ observation of Ce-Cocoated interconnect steel oxidation.

\section{Experimental Method}

The samples were $0.2 \mathrm{~mm}$ thin sheets of Sandvik Sanergy HT interconnect steel, the composition of which is provided in Table I. . A Ce-Co coating was applied by Sandvik Sanergy $(800 \mathrm{~nm}$ Co $+10 \mathrm{~nm} \mathrm{Ce})$ with a proprietary PVD process [40]. 
Table I. Nominal composition (wt\%) given by Sandvik Sanergy

\begin{tabular}{llllllllll}
\hline & Fe & Cr & C & Mn & Si & Al & Mo & Nb & Ti \\
\hline SSHT & Bal & 21.2 & 0.04 & 0.3 & 0.12 & 0.017 & 0.96 & 0.71 & 0.09 \\
\hline
\end{tabular}

\section{$\underline{\text { In-situ observation }}$}

To observe the oxidation in-situ, a FEI quanta 200 ESEM is used. The gas and heating systems were modified as described in previous papers [41], [42]. Oil-free pre-vacuum pumps were installed and all tubing for pumping and gas insertion was replaced by stainless steel tubing. A mass spectrometer was added to analyse the gas composition in the chamber during in-situ reaction.

Regarding the heating system, a laser heats the sample by irradiating its back (the opposite side of the one exposed to the electron beam). For temperature measurement, a thermocouple is directly spot-welded on the conducting sample. Gas flow is controlled with mass flow controllers. One should note that the advantages of such a configuration are fast heating rates and very little drift, compared to the conventional method of heating the support using hot-wire heating stages.

The chamber pressure at an oxygen flow of $5 \mathrm{ml} / \mathrm{min}$ measures $33 \mathrm{~Pa}(0.33 \mathrm{mbar})$. Depending on the heated mass and the heat capacity, the heating system allows heating ramps of several $10^{\circ} \mathrm{C} / \mathrm{s}$.

Sample names are given according to their time and temperature of oxidation as shown in Table II.

Table II. Experimental conditions of in situ exposed and observed samples.

\begin{tabular}{cccc}
\hline Sample name & Heating gas & $\begin{array}{c}\text { Oxidation temperature } \\
\text { as measured by the } \\
\left.\text { thermocouple [ }{ }^{\circ} \mathbf{C}\right]\end{array}$ & Oxidation time [hours] \\
\hline Reference sample & & & \\
IC-45min-800 & $\mathrm{O}_{2}$ & $800+/-10$ & 0.75 \\
IC-6h-800 & $\mathrm{O}_{2}$ & $810+/-15$ & 6 \\
IC-60h-800 & $\mathrm{O}_{2}$ & $805+/-15$ & 60 \\
IC-48h-900 & none & $890+/-20$ & 48 \\
\hline
\end{tabular}

\section{Post test analysis}

After recording images and movies at the site of interest during in-situ experiments, pictures were recorded at the end of the experiments at reduced magnification in order to be able to re-localize the observed regions after transfer of the samples for post test surface observation and target preparation of TEM lamella.

A Zeiss Merlin SEM and Zeiss Nvision 40 Crossbeam FIB-SEM were used for TEM cross section preparation: carbon protection layer deposition, U-shape hole digging around the lamella, lamella extraction with a micro manipulator, carbon welding on TEM grid, thinning with current down to $80 \mathrm{pA}$. 
TEM and STEM observations were done with a FEI Tecnai Osiris TEM optimized with ChemiSTEM EDX technology. EDX-mappings of the zones of interest were acquired for 40 minutes with Esprit software.

\section{Results and Discussion}

In-situ oxidation of the samples results in a surface with two morphologies as shown in Figure 1. About $90 \%$ of the surface is covered by homogeneous and regular grains while the remaining $10 \%$ show islands with much larger grains. The results will thus be presented and discussed in two parts: first the area with smaller grains, then an insight on the larger grain "island" morphology. Finally, the relevance and limitations of the used methods will be discussed.
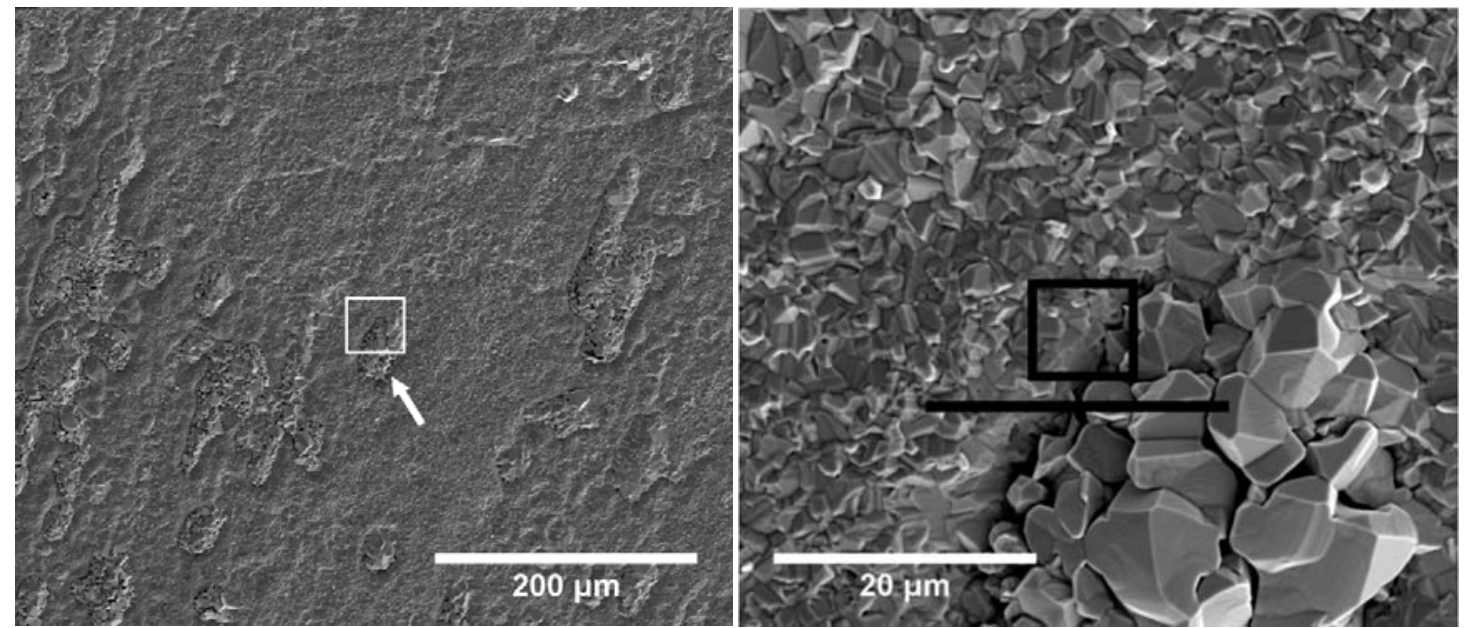

Figure 1: Sample IC-60h-800 oxidised $60 \mathrm{~h}$ at $800^{\circ} \mathrm{C}$ under $33 \mathrm{~Pa}$ of oxygen. Left: overview of the area observed in-situ. The arrow points to the "island" of larger grains that can be observed at higher magnification on the right side image. Right: the square shows the location seen in the movie (Figure 2). The black line shows where the TEM lamella was extracted (Figure 7).

\section{$\underline{\text { Results on the area with smaller grains }}$}

Images extracted from the movie of the in-situ oxidation of the coating observed with ESEM are presented in Figure 2. The growth of the grains can be observed during the first hours. Then, smaller changes continue to occur but at a slower rate, and it is more difficult to see any trend in the size evolution or morphology changes.

From this movie, it is possible to estimate quantitatively the grain size. Since the grains are growing in the three directions of space, the surface is not flat and the contrast changes depending on the orientation of the face of the grain. Hence, each grain contains pixels with very different grey levels and therefore conventional threshold methods could not be applied for computer assisted grain size measurements. The grain boundaries were therefore defined manually. 20 to 50 grains were identified and followed on a series of images at regular times of oxidation. ImageJ was used to calculate the area of each grain. The resulting evolution of the size of the grains is presented in Figure 4. While it is not an accurate estimation of the actual grain size, since the $3^{\text {rd }}$ dimension is missing, it is a means of comparison to quantify the grain growth. It is evident that the growth of the 
grains happens during the first hours, after which the size seems to remain relatively stable. The presence of small grains and the dynamics observed in the movie suggest that recrystallisation occurs.

One can notice that half of the observation window concerns some larger grains belonging to the island presented in Figure 1.

Comparing the resulting surfaces for samples after in-situ oxidation for various times in Figure 3, the grain size evolution is also observable. Between 45 minutes and 6 hours of in-situ oxidation it is clear that the grain size increases. However, the difference between 6 hours and 60 hours is less pronounced which confirms the previous estimation of grain size evolution. The IC-48h-900 surface, Figure 3(d), is different: grains are larger and sharper. The grain morphology of the $800^{\circ} \mathrm{C}$ series suggests a cubic structure while it is more difficult to find this morphology in the $900^{\circ} \mathrm{C}$ oxidised sample IC- $48 \mathrm{~h}-900$.
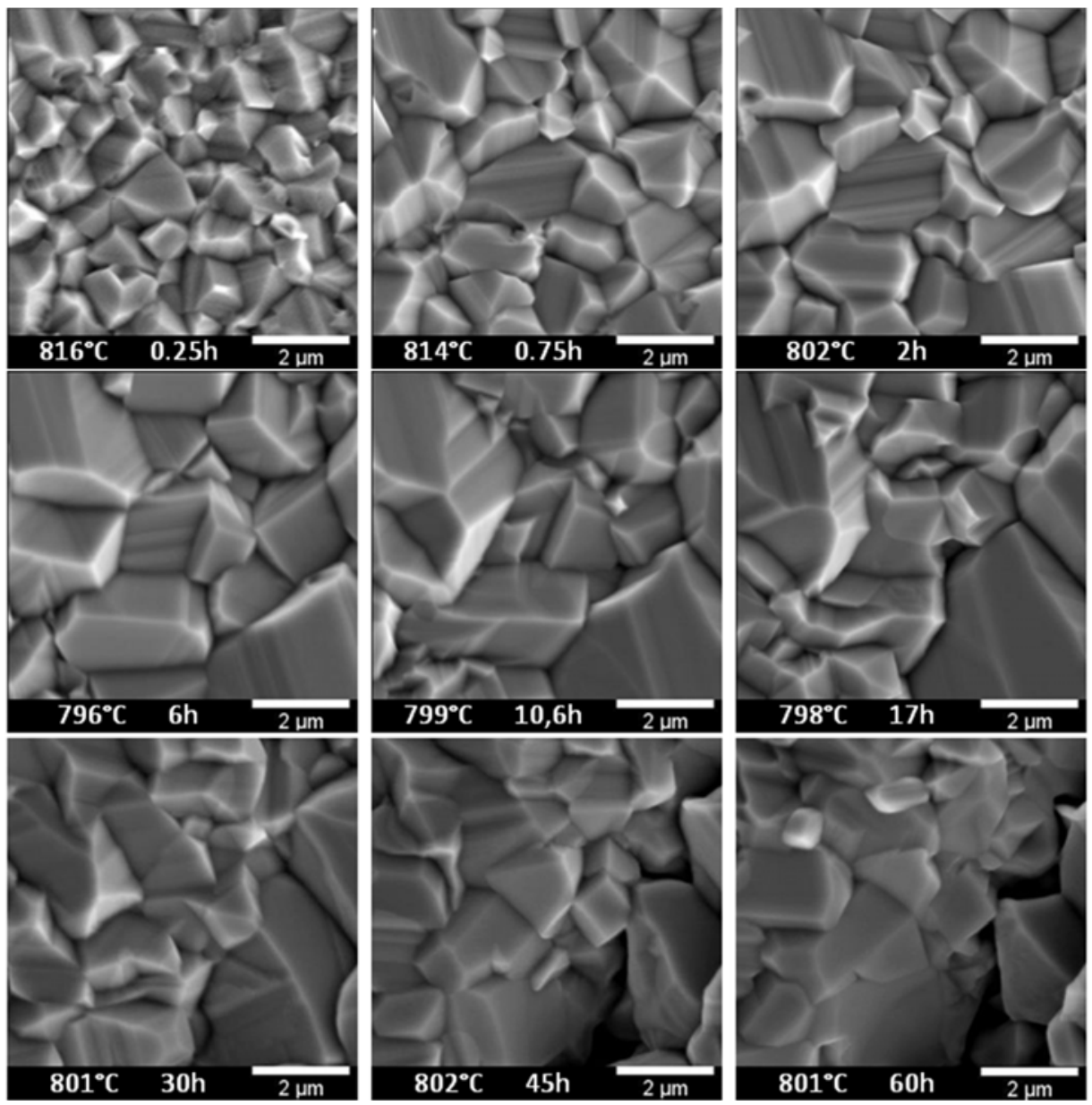

Figure 2: Selected SEM images of the in-situ oxidation of the surface of the cobaltcerium coated steel during 60 hours at around $800^{\circ} \mathrm{C}$ (sample IC-60h-800).

After FIB preparation, TEM images of the cross section of the regular surface structure (Fig. 1-left) of sample IC-60h-800 are presented in Figure 5. Precipitates in the bulk, pores and several layers with various microstructures can be identified. The bulk, at the bottom, contains several precipitates. Above the bulk, some large pores and irregular 
layers are observable. The chromia layer with its polycrystalline structure is also visible and its top half seems porous. Finally, the top layer consists of relatively large grains.
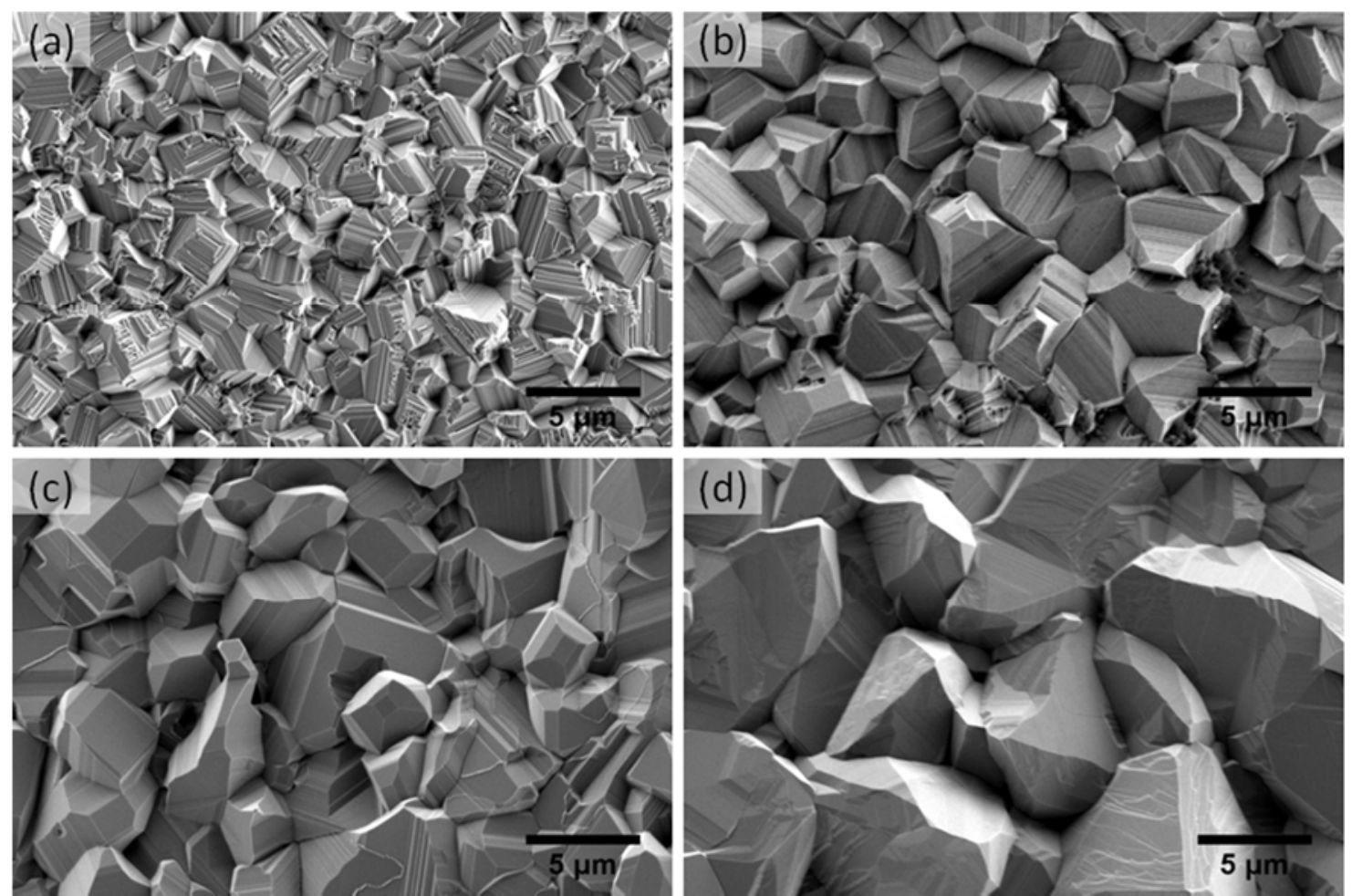

Figure 3: SEM image comparison of the surface of four Ce-Co-coated steel samples after different in-situ oxidation durations at around $800^{\circ} \mathrm{C}$ (a-c) and $900^{\circ} \mathrm{C} \mathrm{(d):} \mathrm{(a)} \mathrm{IC-45min-}$ 800, (b) IC-6h-800, (c) IC-60h-800, (d) IC-48h-900.

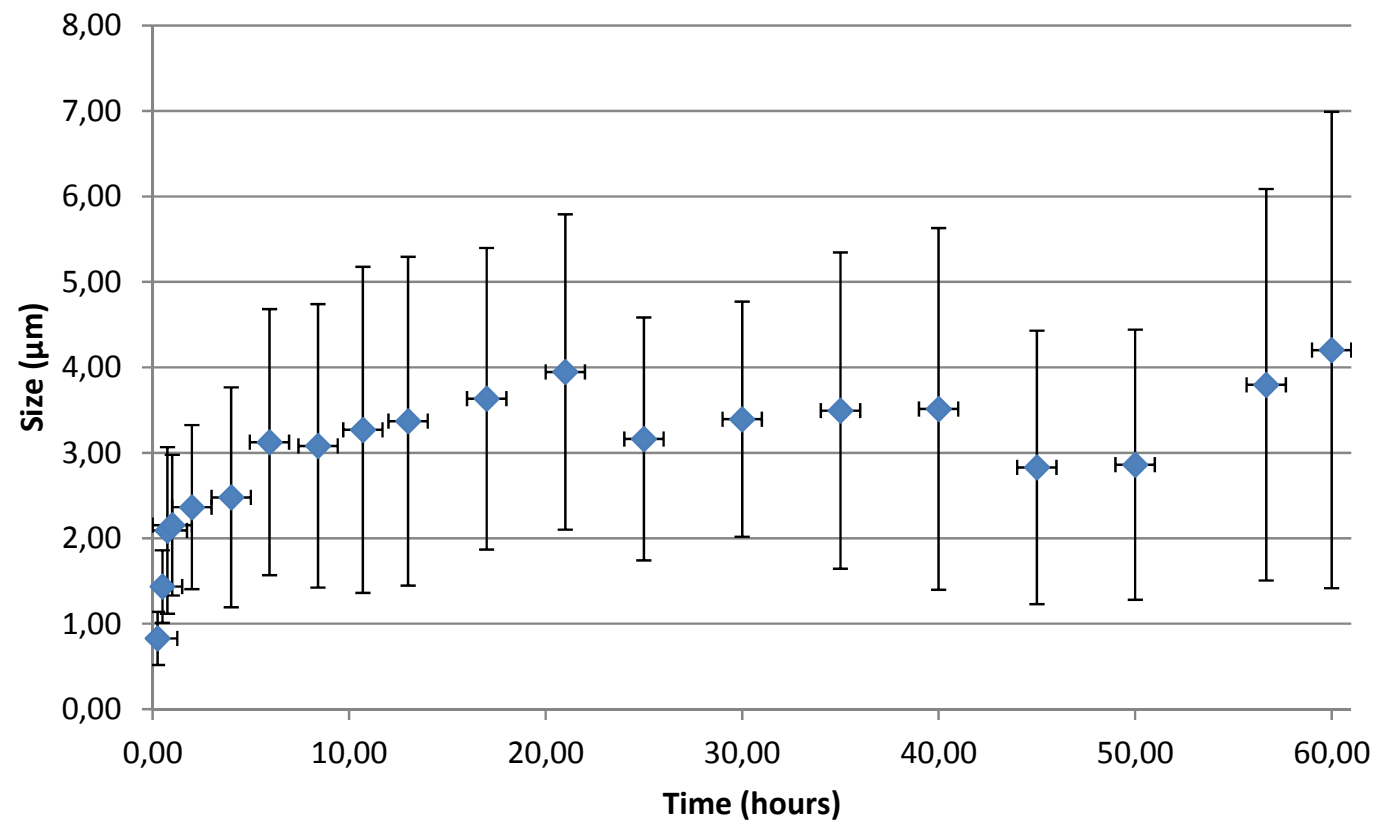

Figure 4: Estimated average size of surface grains during 60 hours in-situ oxidation at around $800^{\circ} \mathrm{C}$ (sample IC-60h-800). The error bars represent the standard deviation. 

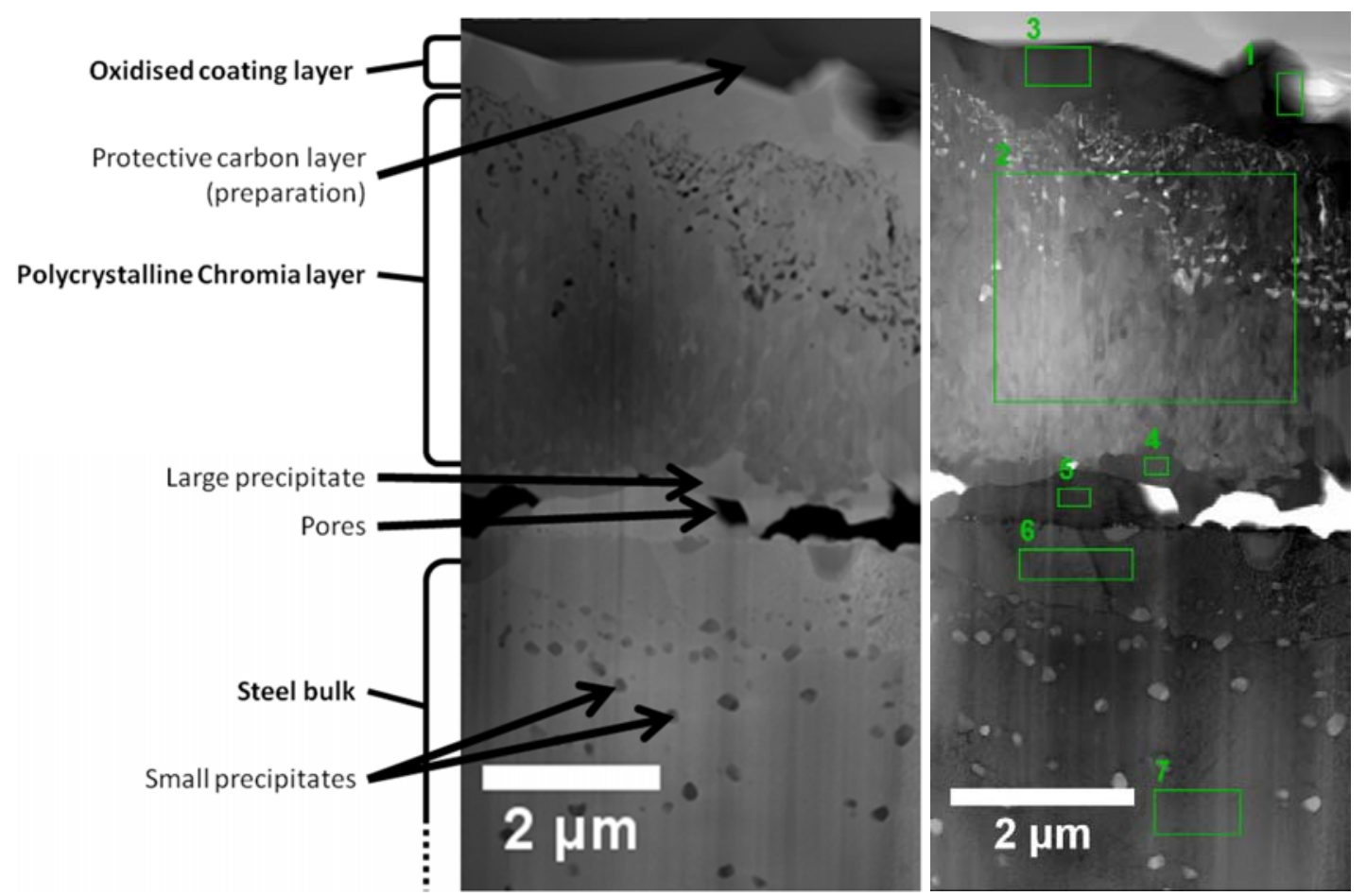

Figure 5: STEM images of the cross section of the regular surface (Fig. 1 - left) of a CeCo-coated steel sample oxidized in-situ for 60 hours at around $800^{\circ} \mathrm{C}$ (sample IC-60h800). Left: HAADF image. Right: BF image with identification of 7 zones quantified by EDX (Table IV).

STEM EDX mapping, as shown in Figure 6, helps in identifying the finer structure of the layers and their composition. Before oxidation, the cobalt coating is homogeneous, polycrystalline and of regular thickness. A very thin layer richer in chromium present between the coating and the steel is probably due to oxidation before/during coating.

During the first 45 minutes, the cobalt crystals of the coating grow and porosity develops between the two initial coating layers. Iron diffuses into the Co-coating while cobalt diffuses in the steel. A $0.6 \mu \mathrm{m}$ chromia layer is formed above the cerium layer. Manganese diffuses from the steel to form a spinel with chromium underneath the cerium layer.

Then, up to the first six hours (Figure 6- middle row), manganese diffuses further, into the coating, to form a Co-Fe-Mn spinel below the Co-layer while more manganese from the steel continues to diffuse to the steel surface and agglomerates below the chromia layer. The chromia layer can be clearly identified and is now $1.5 \mu \mathrm{m}$ thick. The porosity in the top half of the chromia layer appears. The cerium layer still seems to form a continuous layer. However, it is now surrounded by steel (400nm "deep" into the steel). $\mathrm{Nb}$-containing phases (not shown in Figure 6 but indicated in Figure 5 with the composition in Table IV) can also be observed on both sides of the cerium layer. Ti is present in the $\mathrm{Nb}$ precipitates only below the cerium layer.

Finally, after 60 hours of oxidation (Figure 6 - bottom row), almost all the cobalt coating has been converted to Co-Mn-Fe spinel oxide. Some small cobalt oxide crystals remain. The chromia layer has grown to reach a thickness of $3.7 \mu \mathrm{m}$. Nb-Ti precipitates 
(not shown) are forming lines below the coating at several depths. The cerium still forms a layer but it sits deeper in the steel $(600 \mathrm{~nm})$. The larger precipitates form an almost continuous layer with variable thickness under the chromia layer.

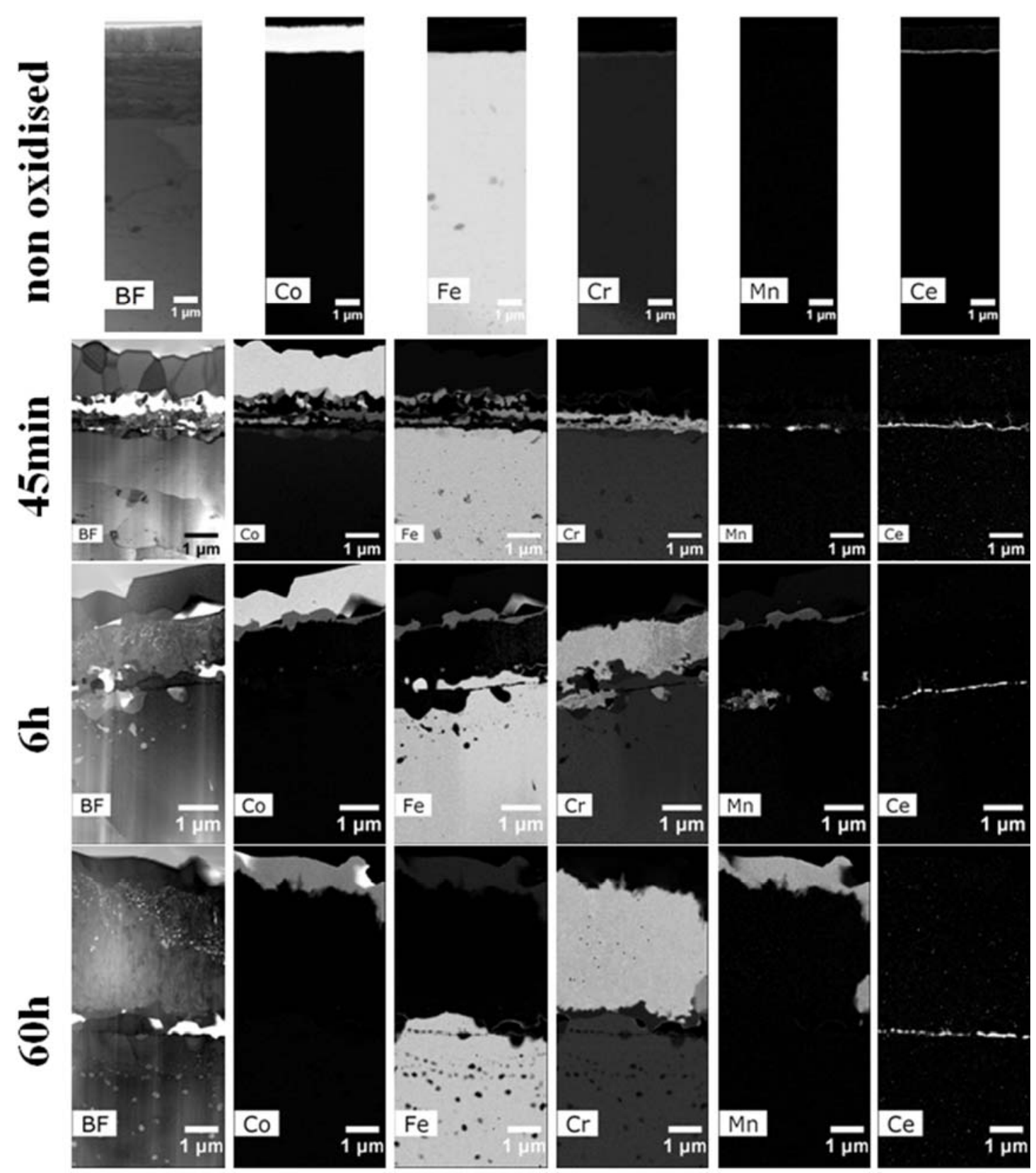

Figure 6: STEM EDX maps of the main elements of the steel before (sample ICref - top row) and after 3 different in-situ oxidation durations at $800^{\circ} \mathrm{C}$ (from top to bottom: samples IC-45min-800, IC-6h-800, IC-60h-800).

The cobalt-coating evolution seems to confirm the model suggested by Froitzheim et al. : the resulting structure and the observed evolution are similar to what he described for cobalt-coated SSHT steel [13]. The cobalt layer is oxidising and then transforming slowly into a Co-Mn-Fe spinel. The chromia layer is growing regularly underneath the coating. Manganese first accumulates below the chromia layer before diffusing to the coating top. 
The growth of the chromia layer in between the steel and the Co-coating is evident. Its thickness seems to increase faster than what was found in literature. Grolig et al., comparing Ce-Co coating to Co-coating $\left(3000 \mathrm{~h}\right.$ ageing at $\left.850^{\circ} \mathrm{C}\right)$, reported $5 \mu \mathrm{m}$ and $10 \mu \mathrm{m}$ thick chromia layers, respectively [22]. Margasó et al. [29] show $3 \mu \mathrm{m}$ and $6 \mu \mathrm{m}$ thick chromia scale after 1000 hours oxidation at $850^{\circ} \mathrm{C}$ for those two coatings. In our study, after only 60 hours at nominally $800^{\circ} \mathrm{C}$ (thermocouple indication in the ESEM), a 3-4 $\mu \mathrm{m}$ thick chromia layer was obtained.

Table III. Measured composition (at $\%$ ) by EDX of the sample before oxidation

\begin{tabular}{cccccccccccc}
\hline Spectrum & $\mathbf{O}$ & $\mathbf{A l}$ & $\mathbf{S i}$ & $\mathbf{T i}$ & $\mathbf{C r}$ & $\mathbf{M n}$ & $\mathbf{F e}$ & $\mathbf{C o}$ & $\mathbf{N b}$ & Mo & Ce \\
\hline Co-layer & 0.6 & 0.2 & 0.3 & 0.0 & 0.4 & 0.2 & 1.0 & 97.1 & 0.0 & 0.0 & 0.1 \\
Steel bulk & 1.2 & 0.1 & 0.2 & 0.1 & 23.3 & 0.5 & 72.8 & 1.0 & 0.3 & 0.4 & 0.2 \\
\hline
\end{tabular}

Table IV. Measured composition (at\%) by EDX of zone 1 to 7 of IC-60h-800, identified on Figure 5.

\begin{tabular}{lccccccccccc}
\hline Spectrum & $\mathbf{O}$ & $\mathbf{A l}$ & $\mathbf{S i}$ & $\mathbf{T i}$ & $\mathbf{C r}$ & $\mathbf{M n}$ & $\mathbf{F e}$ & $\mathbf{C o}$ & $\mathbf{N b}$ & $\mathbf{M o}$ & $\mathbf{C e}$ \\
\hline 1-Co grain & 28.1 & 0.2 & 0.2 & 0.0 & 0.3 & 2.1 & 0.8 & 68.3 & 0.0 & 0.0 & 0.0 \\
2-Chromia & 51.4 & 0.1 & 0.1 & 0.1 & 47.8 & 0.1 & 0.1 & 0.0 & 0.3 & 0.0 & 0.0 \\
3-Co Mn Fe grain & 41.2 & 0.0 & 0.0 & 0.0 & 1.0 & 20.8 & 8.5 & 28.0 & 0.0 & 0.0 & 0.5 \\
4-Nb precipitate & 39.1 & 0.4 & 1.1 & 0.6 & 11.1 & 0.1 & 0.5 & 0.0 & 45.5 & 0.2 & 1.6 \\
5-Steel above Ce & 1.6 & 0.0 & 0.1 & 0.1 & 20.5 & 0.3 & 74.6 & 1.4 & 0.2 & 0.7 & 0.6 \\
6-Steel under Ce & 2.2 & 0.1 & 0.2 & 0.1 & 20.6 & 0.1 & 74.5 & 1.3 & 0.2 & 0.6 & 0.2 \\
7-Steel bulk & 2.9 & 0.0 & 0.1 & 0.1 & 20.4 & 0.1 & 74.5 & 1.2 & 0.1 & 0.6 & 0.0 \\
\hline
\end{tabular}

Concerning the cerium layer, as mentioned above, it was reported to act as barrier against iron diffusion [22] and chromium diffusion [11] . During our in-situ oxidation, it prevented only one element to diffuse through, $\mathrm{Ti}$, the concentration of which is very low in the steel and unproblematic with respect to the SOFC components. The validity of our experiments to represent conditions of interest is discussed further below. Repeating the experiment with alone a cobalt-coated steel will be a way to confirm the effect of the cerium layer. The other beneficial effects from Ce such as decreasing the oxidation rate [26], [27] and slowing down the growth of oxide scale [29], [31], also need a similar comparison for confirmation. Regarding its effect on chromium evaporation [28] and its influence on the conductivity [29], other measurement methods have to be applied.

It is interesting to see how the cerium can penetrate into the steel while staying in the form of a continuous layer - further research is needed in this direction.

The results of the EDX quantification of the substrate steel and coating before oxidation are shown in Table III while quantification of the zones highlighted in Figure 5 are presented in Table IV.

The steel above and below the cerium layer seem identical in composition. The only difference concerns the oxygen concentration. However, oxygen at this depth in the steel is assumed to be only on the surface of the lamella, due to post-preparation oxidation. The contribution of surface oxidation to the EDX signal depends on the ratio between bulk and surface. Since the TEM lamella is very thin, the oxidised surface alone might be responsible for the detected oxygen. 
Further quantifications (not part of Table IV) suggest that the Nb-rich phase above the cerium layer is richer in Si than the other phases of the sample. This would indicate that $\mathrm{Nb}$ traps Si diffusing to the surface, preventing there the formation of $\mathrm{SiO}_{2}$ [17].

\section{$\underline{\text { Results on the island with larger grains }}$}

Areas with larger grains were observable at lower magnification for both the IC-6h800 and the IC-60h-800 samples as shown in Figure 1. In order to simultaneously observe the two types of morphologies, two windows were thinned in the same lamella for TEM observations, as presented in Figure 7.

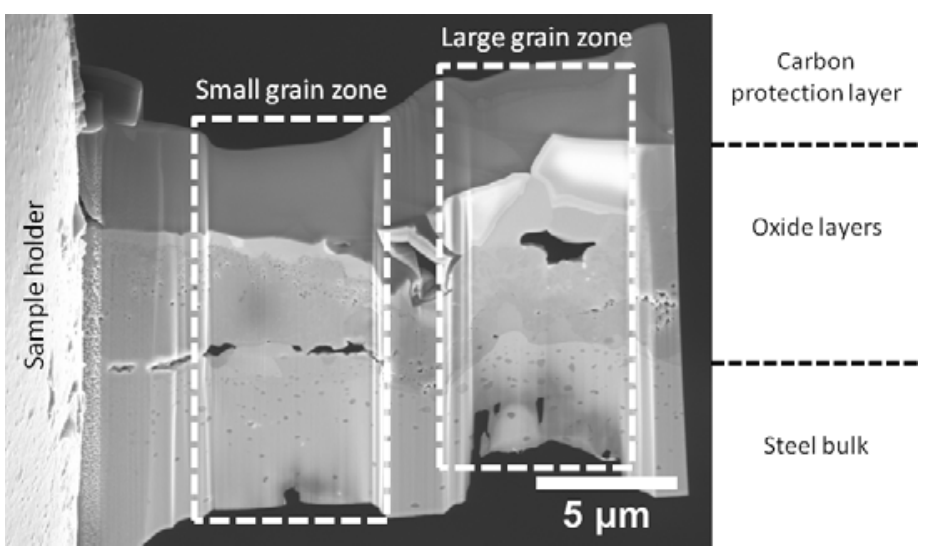

Figure 7: TEM lamella extracted by FIB and welded on sample holder. Two windows, highlighted by white dashed lines, were thinned to observe the two different morphologies of the IC-60h-800 sample (see Figure 1-right, the black line).

In Figure 8, EDX maps of the cross section of the region with larger grains of the IC6h-800 and IC-60h-800 samples are presented. The sub-surface structure of those areas is clearly different from the one observed in the previously discussed 'regular' areas (Figures 5-6). In the EDX-map of sample IC-60h-800 (Figure 8 - bottom), several layers can be identified as follows when listed from the top layer:

- first layer: larger grains made only of cobalt oxide.

- second layer: spinel of Co-Mn-Fe-O with some chromium.

- third layer: similar composition to the previous layer with higher chromium content and chromium rich crystals.

- fourth layer: 'usual' chromia layer.

- fifth layer: a continuous layer made of niobium (not shown as element in Figure 8) but with very irregular thickness.

Cerium does not form a regular layer anymore: it is present in the form of particles between the second and third layer. Those particles seem to be linked to the huge pore that is just above them. Some manganese-rich precipitates are localised in between the fourth and fifth layer.

The structure in the IC-6h-800 sample (Figure 8 - top: 6h exposure instead of $60 \mathrm{~h}$ ) seems already similar although the layers are still much less developed which makes identification more difficult. However, it is important to note that the cerium layer is already dispersed in small particles and that porosity is present above it. 
This unexpected structure was not described elsewhere in the literature, and these differences are as yet unexplained. Indeed, it is not possible to know if the differences between this microstructure and the one observed in the 'regular' area of the samples (Fig. 1 - left) are causes or rather consequences. Further investigation is needed in this direction.

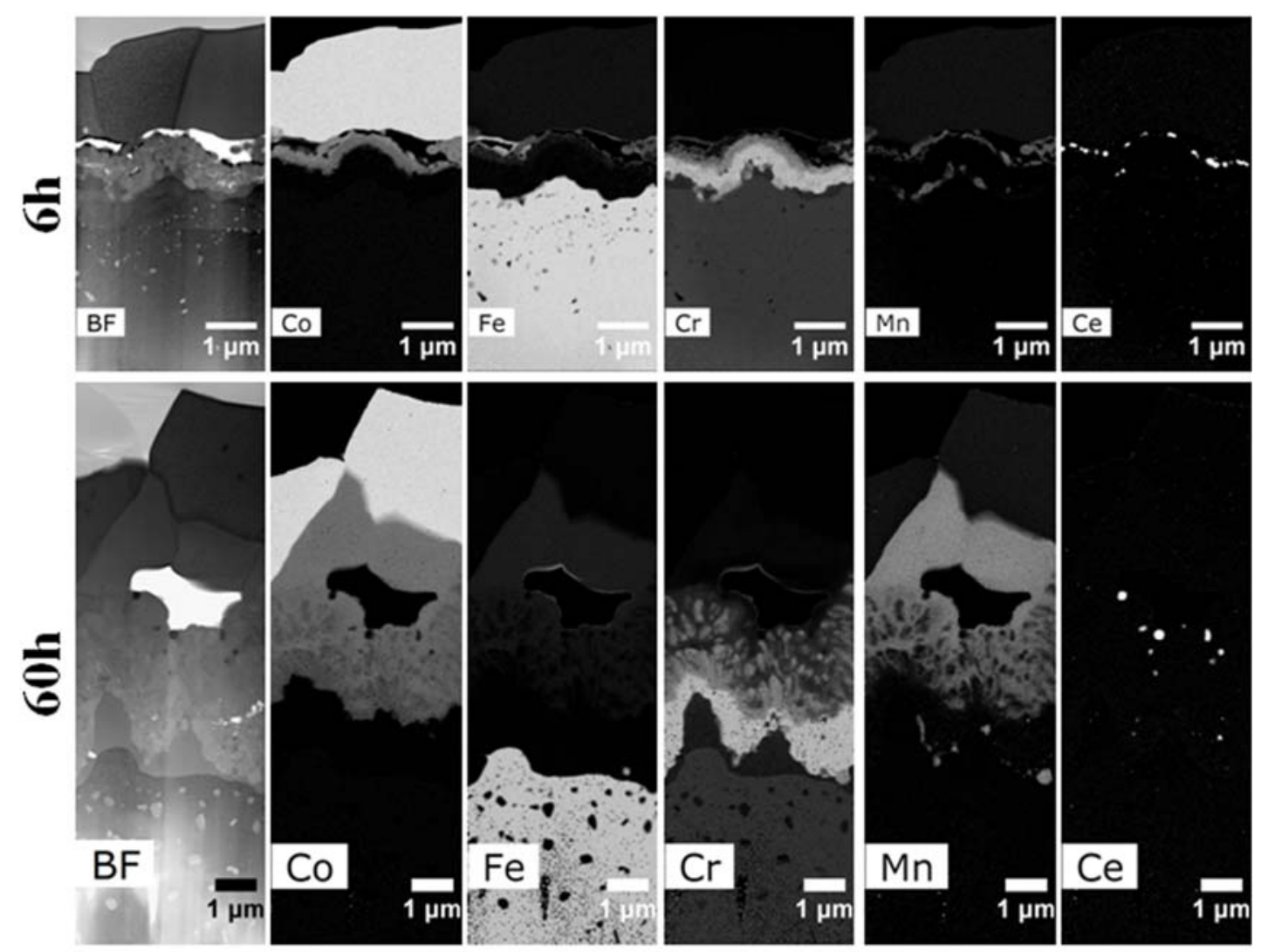

Figure 8: STEM EDX maps of the area with larger grains of the coated steel (cf. Figures1-right) after 6 and 60 hours of in-situ oxidation at $800^{\circ} \mathrm{C}$ (top: IC-6h-800; bottom: IC-60h-800).

\section{Discussion on the ESEM method}

In-situ observation of a steel oxidation process in the modified ESEM instrument presents several advantages. It is possible to monitor directly the reaction-induced evolution of the morphology, keeping the same area in the field of view. This allows to study the reaction kinetics. Also, direct observation of the actual processes by in-situ microscopy eliminates possible artefacts in post-test observation that can occur during cooling and sample transfer. We repeated the experiments several times and found the same oxidation behaviour of the coating as a function of time, demonstrating that the experiments are reproducible. Moreover, the versatility and flexibility of the ESEM allows observation of a wide range of materials and their reactions in defined environments. Imaging over a large pressure range combined with the possibility of using various types of gases with flows controlled by gas-flow meters and composition monitored by mass spectrometry makes this technique applicable for a wide range of studies [41]-[45]. 
The only other study of cobalt-coating (without Ce) with environmental SEM so far was conducted by Skott during his master thesis [36]. The main difference with the ESEM used in our study is the heating stage module, made in Skott's study of a resistance-heated furnace that allows heating of the sample up to $1500^{\circ} \mathrm{C}$ with a ramp of 1 to $50^{\circ} \mathrm{C}$ per minute. The oxidation was conducted in $600 \mathrm{~Pa}$ of water vapour instead of $33 \mathrm{~Pa}$ of pure oxygen. The temperature of the furnace was monitored by a high temperature stage controller. Studying in-situ the oxidation of the cobalt-coating at temperatures between $800^{\circ} \mathrm{C}$ and $1000^{\circ} \mathrm{C}$, they demonstrated the importance of temperature on the final result.

Regarding our experiments, after alignment and cropping of original $20 * 20 \mu \mathrm{m}^{2}$ SEM micrographs of e.g. the IC-60h-800 sample, a movie of a $7.5^{*} 7.5 \mu \mathrm{m}^{2}$ area was obtained (Figure 2). Actually, the whole field of view is 8 times larger, which will help to draw statistical conclusions from the in-situ observation of grain sizes. The reduction is mainly due to drift during acquisition. Shorter times generally allow to maintain a wider field of view: it is easier to regularly compensate the drift.

As described for the grain size quantification, due to the lack of homogeneous contrasts of the grains, a conventional thresholding method could not be used. Manual drawing of the grain is subjective and depends on the user. Hence, so far it was difficult to analyse fine changes in size or morphology. Only general trends can be shown. New methods including machine learning will have to be implemented.

Concerning the temperature measurement during experiments, there are points to clarify regarding temperature gradients across the sample surface and thermal equilibration of the sample in the cold-wall set-up, that need to be compared with experiments in ovens with hot walls and thermocouples placed close to the sample. Reference and calibration experiments in both systems are ongoing and will allow to obtain more accurate results in future which can be compared with literature with higher certainty. The fact that our experiments are reproducible ensures that the calibration of a temperature offset should be sufficient.

Particularly, as highlighted in the literature [32], the involved reactions and diffusion processes are very temperature-sensitive. Hence, the fast growing chromia scale observed in our experiments could be a sign that the real temperature of our sample was higher than the indicated temperature.

One important point for further experiments is to approximate real (atmospheric) conditions as close as possible in the microscope chamber. This means that eventually the interconnects are to be investigated under dual atmosphere conditions [34].

Finally, the influence of pressure has not been discussed in this paper but is of importance. Further tests need to be conducted to validate that results observed in-situ at reduced pressure can indeed be extrapolated to real ageing in atmospheric conditions, as this is still a debated question. 


\section{Conclusion}

We combined in-situ ESEM observations of the oxidation of cerium- cobalt-coating for an SOFC interconnect with time resolved post-test analyses in order to link live surface observations to post-analysed subsurface microstructural evolution and diffusion processes.

The results regarding the evolution of the coating confirm previous studies. Chromia oxide scale grows below the coating, which slowly transforms into a spinel due to the diffusion of iron and manganese from the steel. EDX quantifications also confirm that niobium precipitates are able to trap silicon to prevent the formation of an insulating silica layer.

We saw the appearance of a minority morphology forming on part of the coated steel surface, as islands with larger grains, which could be correlated to locations where the Ce coating was not continuous. However, another mechanism might be at play, that would provoke both the Ce-layer destruction and the larger grain growth. This requires further investigation.

We have demonstrated that ESEM combined with targeted post-test analysis by STEM-EDX of the same zone as studied by ESEM is a very promising methodical approach for in-situ materials studies, with great potential, even if some improvements are still needed: a grain growth quantification method has to be defined in a systematic and objective way, temperature measurement accuracy needs to be assessed and calibrated, and the influence of pressure in the ESEM has to be evaluated by comparison with ex-situ oxidation.

\section{Acknowledgments}

The authors very gratefully acknowledge the MPI-EPFL Center for Molecular Nanosciences and Technology for financial support. Part of the research leading to these results has received funding from the European Union's Seventh Framework Programme (FP7/2007-2013) for the Fuel Cells and Hydrogen Joint Technology Initiative under grant agreement nr. 325331 (project name: SCORED).

\section{References}

[1] J. W. Fergus, "Metallic interconnects for solid oxide fuel cells," Mater. Sci. Eng. A, vol. 397, no. 1-2, pp. 271-283, Apr. 2005.

[2] T. Horita, Y. Xiong, H. Kishimoto, K. Yamaji, M. E. Brito, and H. Yokokawa, "Chromium Poisoning and Degradation at ( $\mathrm{La}, \mathrm{Sr}) \mathrm{MnO}_{3}$ and $\left(\mathrm{La}, \mathrm{Sr}\right.$ ) $\mathrm{FeO}_{3}$ Cathodes for Solid Oxide Fuel Cells," J. Electrochem. Soc., vol. 157, no. 5, pp. B614-B620, May 2010.

[3] J. W. Fergus, "Effect of cathode and electrolyte transport properties on chromium poisoning in solid oxide fuel cells," Int. J. Hydrog. Energy, vol. 32, no. 16, pp. 3664-3671, 2007.

[4] M. Stanislowski, E. Wessel, K. Hilpert, T. Markus, and L. Singheiser, "Chromium Vaporization from High-Temperature Alloys I. Chromia-Forming Steels and the Influence of Outer Oxide Layers," J. Electrochem. Soc., vol. 154, no. 4, pp. A295-A306, Apr. 2007.

[5] R. Sachitanand, M. Sattari, J.-E. Svensson, and J. Froitzheim, "Evaluation of the oxidation and $\mathrm{Cr}$ evaporation properties of selected $\mathrm{FeCr}$ alloys used as SOFC interconnects," Int. J. Hydrog. Energy, vol. 38, no. 35, pp. 15328-15334, Nov. 2013. 
[6] M. Stanislowski et al., "Reduction of chromium vaporization from SOFC interconnectors by highly effective coatings," J. Power Sources, vol. 164, no. 2, pp. 578-589, Feb. 2007.

[7] P. Gannon et al., "Advanced PVD protective coatings for SOFC interconnects," Int. $J$. Hydrog. Energy, vol. 33, no. 14, pp. 3991-4000, Jul. 2008.

[8] F. Smeacetto et al., "Electrophoretic deposition of $\mathrm{Mn}_{1.5} \mathrm{Co}_{1.5} \mathrm{O}_{4}$ on metallic interconnect and interaction with glass-ceramic sealant for solid oxide fuel cells application," J. Power Sources, vol. 280, pp. 379-386, Apr. 2015.

[9] A. M. Dayaghi, M. Askari, H. Rashtchi, and P. Gannon, "Fabrication and high-temperature corrosion of sol-gel Mn/Co oxide spinel coating on AISI 430," Surf. Coat. Technol., vol. 223, pp. 110-114, May 2013.

[10] A. Kruk et al., "Effect of Co deposition on oxidation behavior and electrical properties of ferritic steel for solid oxide fuel cell interconnects," Thin Solid Films, vol. 590, pp. 184-192, Sep. 2015.

[11] S. Canovic et al., "Oxidation of Co- and Ce-nanocoated FeCr steels: A microstructural investigation," Surf. Coat. Technol., vol. 215, pp. 62-74, Jan. 2013.

[12] U. Bexell, M. Olsson, and M. W. Lundberg, "High Temperature Oxidation of Plastically Deformed Ferritic Interconnect Steel," ECS Trans., vol. 35, no. 1, pp. 2463-2470, Apr. 2011.

[13] J. Froitzheim, S. Canovic, M. Nikumaa, R. Sachitanand, L. G. Johansson, and J. E. Svensson, "Long term study of $\mathrm{Cr}$ evaporation and high temperature corrosion behaviour of Co coated ferritic steel for solid oxide fuel cell interconnects," J. Power Sources, vol. 220, pp. 217-227, Dec. 2012.

[14] L. S. Karlsson, M. W. Lundberg, R. Berger, and J. Westlinder, "A Time Resolved Study of Precoated AISI 441 for SOFC Interconnects Using STEM-EELS - Part I," ECS Trans., vol. 68, no. 1, pp. 1657-1665, Jun. 2015.

[15] L. S. Karlsson, M. W. Lundberg, R. Berger, and J. Westlinder, "A Time Resolved Study of Precoated AISI 441 for SOFC Interconnects Using STEM-EELS - Part II," ECS Trans., vol. 68, no. 1, pp. 1667-1679, Jun. 2015.

[16] J. Wu, C. D. Johnson, R. S. Gemmen, and X. Liu, "The performance of solid oxide fuel cells with Mn-Co electroplated interconnect as cathode current collector," J. Power Sources, vol. 189, no. 2, pp. 1106-1113, Apr. 2009.

[17] Z. Yang et al., "Investigation of iron-chromium-niobium-titanium ferritic stainless steel for solid oxide fuel cell interconnect applications," J. Power Sources, vol. 183, no. 2, pp. 660-667, Sep. 2008.

[18] H. Zhang, J. Wu, X. Liu, and A. Baker, "Studies on elements diffusion of Mn/Co coated ferritic stainless steel for solid oxide fuel cell interconnects application," Int. J. Hydrog. Energy, vol. 38, no. 12, pp. 5075-5083, Apr. 2013.

[19] X. Montero et al., " $\mathrm{MnCo}_{1.9} \mathrm{Fe}_{0.1} \mathrm{O}_{4}$ spinel protection layer on commercial ferritic steels for interconnect applications in solid oxide fuel cells," J. Power Sources, vol. 184, no. 1, pp. 172-179, Sep. 2008.

[20] K. Wang, Y. Liu, and J. W. Fergus, "Interactions Between SOFC Interconnect Coating Materials and Chromia," J. Am. Ceram. Soc., vol. 94, no. 12, pp. 4490-4495, Dec. 2011.

[21] G. Jalilvand and M.-A. Faghihi-Sani, "'Fe doped Ni-Co spinel protective coating on ferritic stainless steel for SOFC interconnect application,"” Int. J. Hydrog. Energy, vol. 38, no. 27, pp. 12007-12014, Sep. 2013.

[22] J. G. Grolig, J. Froitzheim, and J.-E. Svensson, "Effect of Cerium on the Electrical Properties of a Cobalt Conversion Coating for Solid Oxide Fuel Cell Interconnects - A Study Using Impedance Spectroscopy," Electrochimica Acta, vol. 184, pp. 301-307, Dec. 2015.

[23] J. G. Grolig, J. Froitzheim, and J.-E. Svensson, "Coated stainless steel 441 as interconnect material for solid oxide fuel cells: Oxidation performance and chromium evaporation," $J$. Power Sources, vol. 248, pp. 1007-1013, Feb. 2014. 
[24] N. Shaigan, D. G. Ivey, and W. Chen, "Co/ $\mathrm{LaCrO}_{3}$ composite coatings for AISI 430 stainless steel solid oxide fuel cell interconnects," J. Power Sources, vol. 185, no. 1, pp. 331-337, Oct. 2008.

[25] A. Balland, P. Gannon, M. Deibert, S. Chevalier, G. Caboche, and S. Fontana, "Investigation of $\mathrm{La}_{2} \mathrm{O}_{3}$ and/or $(\mathrm{Co}, \mathrm{Mn})_{3} \mathrm{O}_{4}$ deposits on Crofer22APU for the SOFC interconnect application," Surf. Coat. Technol., vol. 203, no. 20-21, pp. 3291-3296, Jul. 2009.

[26] M. Sattari, R. Sachitanand, J. Froitzheim, J. E. Svensson, and T. Jonsson, "The effect of Ce on the high temperature oxidation properties of a $\mathrm{Fe}-22 \% \mathrm{Cr}$ steel: microstructural investigation and EELS analysis," Mater. High Temp., vol. 32, no. 1-2, pp. 118-122, Jan. 2015.

[27] S. Molin, A. Chrzan, J. Karczewski, D. Szymczewska, and P. Jasinski, "THE ROLE OF THIN FUNCTIONAL LAYERS IN SOLID OXIDE FUEL CELLS,” Electrochimica Acta, vol. 204, pp. 136-145, Jun. 2016.

[28] J. Froitzheim and J.-E. Svensson, "Multifunctional Nano-Coatings for SOFC Interconnects," ECS Trans., vol. 35, no. 1, pp. 2503-2508, Apr. 2011.

[29] A. Magrasó, H. Falk-Windisch, J. Froitzheim, J.-E. Svensson, and R. Haugsrud, "Reduced long term electrical resistance in Ce/Co-coated ferritic stainless steel for solid oxide fuel cell metallic interconnects," Int. J. Hydrog. Energy, vol. 40, no. 27, pp. 8579-8585, Jul. 2015.

[30] J. Tallgren, M. Bianco, O. Himanen, O. Thomann, J. Kiviaho, and J. Van herle, "Evaluation of Protective Coatings for SOFC Interconnects," ECS Trans., vol. 68, no. 1, pp. 1597-1608, Jun. 2015.

[31] A. Harthøj, T. Holt, and P. Møller, "Oxidation behaviour and electrical properties of cobalt/cerium oxide composite coatings for solid oxide fuel cell interconnects," J. Power Sources, vol. 281, pp. 227-237, May 2015.

[32] H. Falk-Windisch, J. Claquesin, M. Sattari, J.-E. Svensson, and J. Froitzheim, "Co- and $\mathrm{Ce} / \mathrm{Co}$-coated ferritic stainless steel as interconnect material for Intermediate Temperature Solid Oxide Fuel Cells," J. Power Sources, vol. 343, pp. 1-10, Mar. 2017.

[33] A. Safikhani, M. Esmailian, T. Tinatiseresht, and G. B. Darband, "High temperature cyclic oxidation behavior of ferritic stainless steel with addition of alloying elements $\mathrm{Nb}$ and $\mathrm{Ti}$ for use in SOFCs interconnect," Int. J. Hydrog. Energy, vol. 41, no. 14, pp. 6045-6052, Apr. 2016.

[34] A. W. Bredvei Skilbred and R. Haugsrud, "The effect of dual atmosphere conditions on the corrosion of Sandvik Sanergy HT," Int. J. Hydrog. Energy, vol. 37, no. 9, pp. 8095-8101, May 2012.

[35] H. Falk-Windisch, J. E. Svensson, and J. Froitzheim, "The effect of temperature on chromium vaporization and oxide scale growth on interconnect steels for Solid Oxide Fuel Cells," J. Power Sources, vol. 287, pp. 25-35, Aug. 2015.

[36] A. Ø. Skott, "High Temperature Oxidation of Sanergy HT - oxidation kinetics and growth mechanism of a metallic interconnect," 2013.

[37] Y. Nakagawa, K. Yashiro, K. Sato, T. Kawada, and J. Mizusaki, "Microstructural Changes of Ni/YSZ Cermet under Repeated Redox Reaction in Environmental Scanning Electron Microscope (ESEM)," ECS Trans., vol. 7, no. 1, pp. 1373-1380, May 2007.

[38] V. A. M. Brabers and A. D. D. Broemme, "Low-spin-high-spin transition in the $\mathrm{Co}_{3} \mathrm{O}_{4}$ spinel," J. Magn. Magn. Mater., vol. 104, pp. 405-406, Feb. 1992.

[39] Q. Jeangros, "In situ TEM study of reduction and reoxidation of NiO/ceramic composites," Ecole Polytechnique Fédérale de Lausanne, 2014.

[40] "Production process for Sandvik's coated steel strip steel — Sandvik Materials Technology." [Online]. Available: http://smt.sandvik.com/en/products/strip-steel/strip-products/coatedstrip-steel/production-process/. [Accessed: 06-Apr-2017].

[41] Z.-J. Wang et al., "Stacking sequence and interlayer coupling in few-layer graphene revealed by in situ imaging," Nat. Commun., vol. 7, p. 13256, Oct. 2016. 
[42] Z.-J. Wang et al., "Direct Observation of Graphene Growth and Associated Copper Substrate Dynamics by in Situ Scanning Electron Microscopy," ACS Nano, vol. 9, no. 2, pp. 1506-1519, Feb. 2015.

[43] M. T. Greiner et al., "The oxidation of copper catalysts during ethylene epoxidation," Phys. Chem. Chem. Phys., vol. 17, no. 38, pp. 25073-25089, Sep. 2015.

[44] R. Blume et al., "The influence of intercalated oxygen on the properties of graphene on polycrystalline $\mathrm{Cu}$ under various environmental conditions," Phys. Chem. Chem. Phys., vol. 16, no. 47, pp. 25989-26003, Nov. 2014.

[45] N. Nasani, Z.-J. Wang, M. G. Willinger, A. A. Yaremchenko, and D. P. Fagg, "In-situ redox cycling behaviour of $\mathrm{Ni}-\mathrm{BaZr}_{0.85} \mathrm{Y}_{0.15} \mathrm{O}_{3-\delta}$ cermet anodes for Protonic Ceramic Fuel Cells,” Int. J. Hydrog. Energy, vol. 39, no. 34, pp. 19780-19788, Nov. 2014. 